See discussions, stats, and author profiles for this publication at: https://www.researchgate.net/publication/220495975

\title{
Technology and young children: How 4-7 year olds perceive their own use of computers
}

Article in Computers in Human Behavior · July 2010

DOI: 10.1016/j.chb.2010.01.002 · Source: DBLP

\section{CITATIONS}

43

2 authors:

Susan Mckenney

University of Twente

103 PUBLICATIONS 1,825 CITATIONS

SEE PROFILE
READS

947

Joke Voogt

University of Amsterdam

179 PUBLICATIONS 2,883 CITATIONS

SEE PROFILE

Some of the authors of this publication are also working on these related projects:

Project Handbook of Information Technology in Primary and Secondary Education View project

Project EDeR Educational Design Research - An International Journal for Design-Based Research in Education View project 
This is a preprint of: McKenney, S. \& Voogt, J. (2010). Technology and young children: How 4-7 year olds perceive their own use of computers. Computers in Human Behavior 26, 656664.

Technology and young children: How 4-7 year olds perceive their own use of computers

\begin{abstract}
This study examined young children's access, perceptions and use of technology within and outside of school settings. 167 children from varied ethnic and socioeconomic backgrounds participated in the study. Regardless of gender, socio-economic status or ethnic group, most children had access to computers in and outside of schools. In both settings, pre-K through grade 2 children report that they primarily use computers to play games. Children's attitudes toward computers are positive. Older children tend to use the computer more often, are better able to operate the computer and their attitudes towards computers are more positive. Boys' attitudes towards computers are more positive than the attitudes of girls, but no gender differences were found for computer use nor ability level. While no significant differences were found between the attitudes of Dutch and immigrant children, the latter group indicated more frequent use. Also, children from a lower socio-economic neighborhood had more positive attitudes towards computers and used computers slightly more often than middle class children. The findings of this study inform the debate on the desirability of young children's exposure to computers at home as well as in educational settings. Further, these findings may help educators and parents to both critically assess their current practices (e.g. the relative value of the most frequently used applications - games), and strive to integrate developmentally appropriate uses of technology at home and in classrooms.
\end{abstract}

\title{
Keywords (up to six)
}

Kindergarten, elementary school, computer, technology, gender, ethnicity 


\section{Introduction}

In the past century, the introduction of new media such as films, radio and television, has spawned debate and research concerning the (educational) benefits for children versus the fears related to (over)exposure (Wartella \& Jennings, 2000). In this millennium, the opportunities and concerns regarding widely accessible Information and Communications Technologies (ICTs) are no different. Society's perceptions of technology and expectations for its use are important (Siu \& Lam, 2005). Those notions impact the use of computers at home, as well as shape the course of implementation in educational settings. While many assert that computers do not have a place at the hands of young children (Cordes \& Miller, 2000), others contend that those who do not embrace new media may be in danger of losing touch with the popular culture of young children and their families (Yelland, Neal \& Dakich, 2008).

While the debate in favor of and against young children's computer use rages on, there is little dispute that today, children are using computers even before they know how to read and write. However, research is lacking on how young children use computers (Judge, Puckett, \& Cabuk, 2004; Plowman \& Stephen, 2003) and what the (intentional and unintentional) effects are. This is especially true in the Netherlands. Current literature is dominated by investigations conducted in the United States (Aubrey \& Dahl, 2008). Studies involving young children and computers have increased in recent years, with greater emphasis on exploring innovative applications for this age range (e.g. de Jong \& Bus, 2004; Pelletier, Reeve, \& Halewood, 2006; Siraj-Blatchford \& Siraj-Blatchforrd, 2002) and only a few examining usage patterns (Brooker \& Siraj-Blatchford, 2002; Marsh, 2004; Marsh et al., 2005; Plowman \& Stephen, 2007). Of those studies that look at how children are using computers, most rely on parent and caregiver reports; and very few involve asking children 
directly about how they perceive their own use of computers. In analyzing the 60 structured interviews and 1852 questionnaire responses from parents and caregivers in the England, Marsh and her colleagues (2005) found:

- Frequency: $53 \%$ the children in the $0-6$ age range use computers on a typical day, usually for less than one hour.

- Type: Children's favorite type of application was playing games, either on websites (especially those associated with $\mathrm{BBC}$ television programs) on CD/DVD.

- Gender: When listing website favorites, boys' and girls' preferences were the same for the first three rankings (CBeebies, $\mathrm{CBBC}$, and Nickolodeon Junior, respectively), but differed in the fourth and fifth rankings. Boys preferred Bob the Builder and Thomas the Tank Engine, while girls liked Barbie and the Tweenies.

- Parental attitude: Parents were overwhelmingly positive about their children using computers, noting their acquisition of computing skills as well as software-specific knowledge and skills as beneficial. Concerns about the children using computers were not expressed.

Perhaps even more problematic is the prevalence of "few facts and many opinions" about the use of computers by young children (Skeele \& Stefankiewicz, 2002, p. 80). The need for increased research into young children's computer use has been expressed by researchers and practitioners. Though early, this call is garnering response, as exemplified by programs and projects undertaken on both sides of the Atlantic such as:

- Technology and Young Children Special Interest Forum within the [American] National Association for the Education of Young Children (NAEYC); and

- Children's Awareness of Technology (CHAT) and Developmentally Appropriate Technology in Early Childhood (DATEC), sponsored by the European Union. 
As early as the 1990s, Knezek, Miyashita and Sakomoto (1996) studied young children's attitudes towards computers. Data were collected from 1990-1994 and examined the impact of computer use on children in grade 1-3 (6-9 year olds) from Japan, the USA and Mexico. The results showed that computer exposure in school had a positive impact on children's attitudes towards computers and that children's perceptions of computers were not related to their home country. Studies such as this have not been conducted in the Netherlands. Therefore, the research reported in this paper focuses on computer attitudes, computer use and computer skills of pre-K-grade 2 children (4-7 year olds), an age range slightly younger than the children who were involved in the study reported above. Better insight in computer use and attitudes of young children informs the debate of the desirability of young children's exposure to computers at home as well as in educational settings.

As with any educational resource, equitable use is worthy of consideration. Although Knezek et al. (1996) did not find gender differences in attitudes towards computers for children in grade 1-3, girls' participation in technology-related activities has been a serious concern in the last decade (cf. AAUW, 2000; Meelissen, 2008). Perhaps even more disquieting is the 'digital divide,' now generally defined as "situations in which there is a marked gap in access to or use of ICT devices," (Campbell, p.1 in Resta \& Laferriere, 2008). The digital divide usually exists when a group's access to ICT differs along one or more dimensions of socio-, economic, cultural, or national identity (Resta and Laferriere, 2008). In this study, we explore whether indications can be found for a digital divide in this age range with respect to gender, socio-economic status and (ethnic) minority versus (ethnic) majority groups in the Dutch society. Studies with older children have shown that lower-income students have less access to computers in the home, and use computers at school more often for repetitive practice; 
whereas higher-income students have far greater access to computers in the home and use computers at school more often for more sophisticated, intellectually complex applications (Becker, 2000). Aside from the notable exception of the Brooker and Siraj-Blatchford work, (Brooker \& Siraj-Blatchford, 2002), very few of the already scarce studies looking at computer use in this age range, examine the access to ICT with regard to gender and ethnic minorities (Plowman \& Stephen, 2003). What we do know from the work of Brooker and Siraj-Blatchford (2002) is that they found, of the 48 children (and their parents) who participated in the study:

- Considerable inequality of access to ICT in the home: In this study, 28 children were from English families, 17 from Bangladeshi families, and 3 from another ethnic origin (African and Kosovan). 26 of the 48 households contained a computer, but only 3 of these were in Bangladeshi homes.

- Young girls are as likely as young boys to be using a home computer.

- Middle-class parents tend to be more involved in their children's computer use than lower class parents.

- No evidence that home advantages in terms of technology access directly influenced computer use at school.

The finding that girls and boys are equally likely to be using a home computer is consistent with the findings of a previous study (Siraj-Blatchford \& Siraj-Blatchford, 2001). However, the finding that home advantages do not influence computer use at school is especially interesting, as it is contradicted by the beliefs of early years educators who responded to an earlier Siraj-Blatchford \& Siraj-Blatchford survey.

The study reported in this article took place in the Netherlands, and speaks to the need for better insight into how children are using computers, how they experience computers, and 
differences associated with gender and ethnicity. With the ultimate aim of understanding how Dutch 4-7 year olds perceive their own use of computers, the following four research questions were formulated:

1. Is access to computers outside school associated with gender, age, socio-economic status or ethnic group?

2. What activities do young children do on the computer, in and out of school?

3. To what extent are they able to conduct these activities independently or with help?

3. What attitudes do young children have?

4. Are differences in the use, skills or attitudes associated with gender, age, socio-economic status and ethnic group?

\section{Methods}

\subsection{Participants}

Children in pre-kindergarten (pre-K) through second grade (Dutch groups 1-4) from two schools participated. In total, 167 children ( 82 boys and 85 girls) were involved in the study. The age range varied between 4-8 years. The Dutch school system starts at the age of 4 when children start in pre- $\mathrm{K}$, and is compulsory from kindergarten $(\mathrm{K})$ starting at age 5 . In the Netherlands, $98 \%$ of all 4 -year olds attend pre-K. In this study we explored in and out of school use of computers. For this reason we prefer not to use age level, but to use grade level as an indicator of age. In the Dutch school system most four year olds attend pre-K, most 5 year old attend $\mathrm{K}$, the 6 year olds are in grade 1 and the most 7 year olds are in grade 2. Learning to read and to write, as well as basic arithmetic starts in grade 1, but preparatory activities are carried out in pre- $\mathrm{K}$ and $\mathrm{K}$.

Regardless of nationality, children were classified as native Dutch or Dutch immigrants. In accordance with national guidelines, native Dutch children were defined as those whose 
parents were both born in the Netherlands; children of one or more parents born in another country were categorized as Dutch immigrants. Both schools were located in the same city of 150,000 . One school, hereafter referred to as "Southside," is located on the outskirts of town, in an area of lower socio-economic status and many second and third generation immigrant families from Morrocco or Turkey with Arab-Berber or Turkish ethnic backgrounds, respectively. Teachers in this school openly share their ongoing concerns about pupil welfare and regularly conduct home visits. 81 children from this school participated in the study. 36 were classified as Dutch natives, and can be considered as belonging to the ethnic majority; while 45 were classified as immigrants and belonging to the ethnic minorities present in this part of town. In this study, we consider the immigrants of Southside to represent ethnic minorities and compare them with the Dutch natives from Southside as a representation of an ethnic majority group.

The other school, hereafter referred to as, "Central," is located in the city center, with primarily middle class children attending. Pupil welfare issues are less common in this school, and home visits by teachers are rarely made. This school is the only school in the region that offers instruction in English for long-term visiting children whose parents work in international companies or at the local university. Children attend the English language class a few hours each day, but spend the majority of their time in their home class with the Dutch children. In addition, the school prides itself on their Early English program, teaching English as a second language to Dutch-speaking children from pre-K onwards, which is exceptional in the Dutch education system. From this school, 86 children participated, with 58 classified as Dutch natives (ethnic majority) and 33 as immigrants. It should be noted, however, that this group of immigrants is much more mixed than those from Southside, and cannot be classified as an ethnic minority group. 
Dutch public primary schools receive financing from the national government based on the total amount of children enrolled, with additional subsidies for children at risk. The at-risk subsidies are based on the population of learners in need within each school. Different "weights," corresponding to different levels of financial compensation, are calculated for individual children, and the percentage of children at each "weight" determines the amount of additional financing a school may receive. Prior to 2006, the "weights" were based on ethnicity and parental form of employment. In August 2006, this program was heavily revised and is now based solely on the care-giver level of education. In our 2007 study, the type of neighborhood and percentage of "weighted" children was used to classify the socio-economic status of the school population. With $80 \%$ of Southside's student population containing "weighted" children, compared to $4 \%$ at Central, we view the Southside population to represent low socio-economic status and the Central population to represent middle socioeconomic status.

Both schools had similar technology facilities: one or two computers in each classroom and computer clusters in one or more hallways. Southside has a technology coordinator who manages the infrastructure and also worked with the children on a weekly basis. This school prides itself on their approach to technology integration, which begins with the pre-K groups. In contrast, Central assigns the role of technology coordinator to a regular classroom teacher, whose main task is to manage the infrastructure including, when necessary coordination with the service provider. Both schools used the same third-party provider for technology services. 


\subsection{Data collection}

In a preliminary study conducted in 2003, experience was acquired in collecting data with children of this age level. The data for this study were collected through one-on-one interviews with the children. The interviews contained closed questions and were designed to take less than 15 minutes each. They addressed five areas: demographics, computer availability/access, computer activities use, attitudes and abilities. The experiences with the data collection in 2003 were used to improve the data collection in 2007. In Table 1, an overview is presented of the changes that were made.

-----Insert Table 1 about here-----

Demographics. The demographics section included name, class, school, grade, age, gender, land of birth (of self and parents) and language spoken at home.

Computer availability, access and activity types. The questions in this section were based on a selection of questions used in a Dutch questionnaire (Ten Brummelhuis \& Drent, 2000) for monitoring computer use. For school and at home, the computer activities section included the following categories of activities: practicing words/math; drawing; writing letters/stories; playing games; searching for information on Internet; reading/writing e-mail; and chatting (this last one was only asked for at home, as schools do not allow this practice). In 2003, children were asked to indicate if they did these things every day, every week, less often or never. Based on the experience in 2003, the interview was simplified in 2007 and instead, the classifications often (daily or weekly), sometimes (less than once a week), or never were used. In the 2007 study, the list of computer activities in school did not form a coherent scale (Cronbach's $\alpha=0.40$ ), but the internal consistency for out of school computer use was quite acceptable (Cronbach's $\alpha=0.72$ ). Children were also asked where they used the computer 
most (e.g. home, school, library, friend's house) and what facilities were available at home (computer, Internet).

Attitudes. The attitude section was based on the computer importance and computer enjoyment subscales from the Young Children's Computer Inventory (Knezek, Miyashita \& Sakomoto, 1996), designed for first through third graders. A version that more closely resembled the original was used in 2003, but researcher observations and consistency values showed it was too long for the age group in our study. In 2007, this section was shortened, to be usable also for kindergarteners as well (four and five year olds). The internal consistency for the 2007 attitude scale was determined to be acceptable (Chronbach's $\alpha=0.69$ ). Skills to use the computer independently. This section was completely new in the 2007 study. Children indicated how they used each computer activity: independently, with help, or neither (meaning, not at all). The internal consistency, Chronbach's $\alpha=0.67$ ) of this scale was considered acceptable. This scale represents children's perceptions of their competency levels in using software applications.

-----Insert Figure 1 about here-----

Except for the demographic information, black and white icons on colored cards were used to help the learners understand and stay focused on the interview questions. For example, children were shown the school icon card and then asked, "While at school, do you use the computer?" If they said yes, then a yellow set of cards was shown, two of which are pictured in Figure 1. Children were then told what each one meant, then asked to turn face-down the ones that represent activities they did not do. For the remaining activities, children were asked if they did this often (daily or weekly) or sometimes (less than once a week). Children were first given practice questions on how often they watch television or go to the movies. 


\subsection{Data analysis}

The interviews were conducted with 2 trained interviewers. They used the icon cards when asking each question to a child and based on the child's answer completed the questionnaire. Internal consistency measures were calculated for the different sections of the questionnaire. Descriptive data were calculated for the responses to computer activity both in and out of school, as well as the ability levels and attitudes. An independent t-test was used for comparing attitudes with regard to gender, socio-economic status, ethnic group and grade level (youngest - oldest). Besides means and standard deviations, effect sizes (Cohen's d) were also calculated. Cohen (1969) provided tentative benchmarks for the interpretation of effect sizes. He considers $\mathrm{d}=0.2$ a small, $\mathrm{d}=0.5$ a medium and $\mathrm{d}=0.8$ a large effect size.

\section{Results}

\subsection{Access to computers outside school}

While both schools have computer facilities for use by the children, we were more interested in the availability of computers for children at home. The results, presented in Table 2, show that the penetration of computers at home is very high. It is notable that there is a relatively low presence of computers (computers with Internet access in particular) in the homes of Dutch native children in Southside. However, the overall picture is that most children do have access to a computer, often with Internet access, in their homes.

-----Insert Table 2 about here----- 
If you ask the children where, outside school, they mainly use the computer, most of them report that they use the computer at home (see Table 3). A few also use the computer mainly at a friend's house or at school (after school hours). Almost $10 \%$ of children in pre-K report not using the computer outside of school. Also, (relatively few) girls report more often than boys that they do not use the computer outside school.

-----Insert Table 3 about here-----

\subsection{In and out of school computer use: activities}

Before exploring the use of computers in school and outside school with regard to gender, grade level, ethnic group and socio-economic status, an overview of the percentage of children that report 'never' to use a specific computer activity is presented in Table 4 . The findings show that only a few children report never to play a computer game, but that many at this age level never search the Internet or read or write e-mail.

-----Insert Table 4 about here-----

In Table 5, differences between boys' and girls' use of computers are presented. Boys and girls do not differ a lot in the kind of use of the computer. Both boys and girls report that in school and outside the school they use the computer most often for 'playing a game'. This is followed by 'practicing words/math' (in school use) and 'searching the Internet' (out of school use). 'Reading and writing e-mail' is the least often mentioned use of the computer in this age range both in school and outside school. Although the majority of the children (both boys and girls) never chat on the computer, 'chatting' is fairly often mentioned by about $40 \%$ of the children as an activity they do on the computer. 
Medium-medium ${ }^{+}$effect sizes in favor of boys were found for 'drawing' $(\mathrm{d}=0.31)$; 'writing a letter/story' $(d=0.26)$, 'playing a game' $(d=0.19)$, indicating that boys use the computer in school for these activities more often than girls. With regard to out of school use, a medium ${ }^{+}$ effect size $(\mathrm{d}=0.25)$ was found in favor of boys for 'searching the internet' and a medium effect size for 'drawing' in favor of girls.

-----Insert Table 5 about here-----

Tables 6 and 7 present the results of the activities children carry out on the computer according to grade level. With regard to in school use, children report that 'playing games' is most often used in the lower grades (4-5 year olds), but in the middle grades (6-7 year olds) 'playing games' and 'practicing words/math' is about equally reported. The other activities are mentioned considerably less. A large effect size $(\mathrm{d}=0.78)$ between pre-K and grade 2 , in favor of the latter, is found for 'practicing words/math', it indicates that in the middle grades compared to the lower grades the computer is more often used for school-based activities. Also 'writing a letter/story' is mentioned considerably more in grade 2 compared to pre-K (medium-large effect size; $\mathrm{d}=0.35$ ), which makes sense, because pre-K students usually do not have formal writing skills. A medium ${ }^{+}$effect size $(\mathrm{d}=0.26)$ of 'playing a game' in favor of pre-K indicates that games are more often used in the lower grades.

-----Insert Table 6 about here-----

Table 7 presents the results for computer use outside school. The effect sizes $\left(\right.$ medium $^{+}$large ${ }^{+}$) show that outside school, an increase in use is found for all distinguished computer 
activities for grade 2 children compared to children in pre-K. 'Playing games' clearly is the most frequent use of the computer across grade levels. Followed by 'searching the Internet (pre-K, grade 1 and grade 2) and 'drawing'(K).

-----Insert Table 7 about here-----

Table 8 presents the results with respect to ethnic majority/minority. The overall picture is the same: both groups use the computer most often for playing games, both in school and outside school. Concerning the use of computers in school, differences between the two groups with medium to large effect sizes for writing letter/story and playing a game, suggesting that Dutch natives at Southside use the computer in school for these activities more often than their immigrant peers. For the other activities, no differences were found between the two groups. However, out of school computer use provides a very different picture. Immigrant children seem to use the computer more often for quite a number of activities. Medium-large ${ }^{+}$effect sizes were found for searching the Internet, practicing words/math; playing a game, and chatting. The only activity for which Dutch native children report more frequent use than their immigrant peers, is 'writing a letter/story' $(\mathrm{d}=0,18)$.

-----Insert Table 8 about here-----

Table 9 presents the results with respect to socio-economic status. The picture that emerges throughout is the use of the computer for playing games, which seems the most favorite use for children from both schools. With regard to in school use, children attending Southside use the computer more, compared to Central children, for 'drawing' $(\mathrm{d}=0.90)$, while children at Central use the computer more for searching the Internet $(\mathrm{d}=1.01)$, and reading./writing e- 
mail $(d=0,24)$. It should be noted however that e-mail use does not happen very often in both schools. The picture for computer use outside school is different. Southside children use the computer more for chatting $(\mathrm{d}=0.81)$; drawing $(\mathrm{d}=0.42)$, writing letter/story $(\mathrm{d}=0.34)$ and reading/writing email $(\mathrm{d}=0.32)$ compared to their peers from Central, while Central children use the computer, more for playing games $(\mathrm{d}=0.29)$.

-----Insert Table 9 about here-----

\subsection{Skills to operate the computer independently}

We asked the children whether they were able to operate the computer for particular activities by themselves (alone), with help or not at all. The results, presented in Table 10 show that the majority of both boys and girls in this age range are able to play a computer game, start a computer game, make a drawing and search on the Internet alone or with some help.

Differences in skills between boys and girls, with small ${ }^{+}$effect sizes, were found for starting a computer game ( $\mathrm{d}=0.25$ in favor of boys), writing a letter/story $(\mathrm{d}=0.25$, in favor of girls $)$ and searching for information (d-0.21 in favor of boys).

With respect to grade level, the results show that the majority of the youngest children in pre$\mathrm{K}$ are already able to start and play a game (with help or alone). However, it is striking that already at this age level (most pre-K children are 4 years old) so many children report being able - often with help - to handle the computer. It far less surprising that this has changed by grade 2 (most children are then 7 years old). In grade 2 , the majority is able to use the computer (with help or alone) for all the different skills that were distinguished. The difference between pre- $\mathrm{K}$ and grade 2 children is expressed in the effect sizes, which are 
large ${ }^{+}$in favor of grade 2 children, for most skills, except for playing a computer game and making a drawing, where the effect size is medium (in favor of grade 2).

-----Insert Table 10 about here-----

Table 11 presents differences in skills for operating the computer for the activities distinguished, with respect to ethnic group and socio-economic status. The results show that the majority of children in both ethnic groups (Dutch natives and immigrants) are able to start and play a computer game and to make a drawing. The majority of the immigrants at Southside are also able to search for information on the Internet. Small ${ }^{+}-$large $^{+}$effect sizes in favor of the immigrants of Southside were found for starting a computer game $(d=0.30)$, playing a computer game $(\mathrm{d}=0.23)$, making a drawing $(\mathrm{d}=0.34)$, searching the Internet $(d=0.85)$ and chatting $(d=0.24)$.

-----Insert Table 11 about here-----

With regard to socio-economic status, we did find differences with small-medium ${ }^{+}$effect sizes in favor of Southside with regard to making a drawing $(\mathrm{d}=0.26)$, reading/writing e-mail $(d=0.19)$ and chatting $(d=0.60)$. But, Central children report being more able to write a letter/story $(\mathrm{d}=0.25)$ compared to their Southside peers.

\subsection{Attitudes}

Overall, children express positive attitudes towards computers $(\mathrm{M}=3.23, \mathrm{SD}=0.56)$.

Significant differences in attitudes (see Table 12) towards computers were found for gender (in favor of boys), grade level (in favor of the older children in grade 2) and socio-economic status (in favor of the children from a lower socio-economic neighborhood, Southside). 
-----Insert Table 12 about here-----

\section{Discussion and conclusions}

Examining how young children perceive their use of computers provides information for educators and parents, many of whom are struggling to find practical, developmentally appropriate applications of technology in classrooms and at home. This study set out to explore young children's access to computers, their perceptions of what they do on the computer (in school and outside school), their abilities to operate the computer for specific activities, and their attitudes towards computers. Given the limited scope of the study (two schools in the Netherlands) only tentative conclusions can be drawn. Additionally, two other limitations to the study bear mention. First, the audio visual aids that were used (icon cards) require some abstract thinking; it is possible that the icons could have introduced some kind of influence on children's affective judgment of the activities represented. Second, more triangulation involving multiple methods could have helped to mitigate this potential weakness and strengthen the other findings.

The findings of this study showed that most young children had access to computers, regardless of gender, socio-economic background or ethic group. These findings are consistent with 2007 figures from the Dutch Central Bureau of Statistics, which reported 98\% of all households having computers and $96 \%$ of all households having Internet access (CBS, 2007). The findings of this study suggest that the digital divide with regard to computer 
access is not so much an issue anymore in the Netherlands, but more large scale studies are needed to confirm this conclusion.

Regardless of gender, age, socio-economic status and ethic group, playing games is the computer activity young children most frequently do, both at home and at school. As playing games is the most common way for children of all ages to spend their free time, it is not surprising that children report playing games as the most frequent computer activity at home both in this study and in research with older children (Becker, 2000). Next to playing games, searching the Internet is the second most-frequently reported activity for out of school computer use. The other activities are carried out less often.

It is notable that children report that they also use the computer most for playing games while at school. Children in pre-K (4 year olds) play games in school more often than their peers from grade 2 ( 7 year olds). These results may imply that the computer in school is used as a bonus for children who are finished with their school tasks and are allowed to play a game on the computer. However, it is also possible that especially the younger children experience their activity as a game, even though their teachers might differently describe the same software, due to its affordances with regard to, for example, learning or practice in the area of (preparatory) literacy or numeracy. Further research is necessary to better understand this finding. Next to playing games, practicing words/math is the second reported use of the computer in school. This computer activity increases with grade level. Except for drawing on the computer, the other activities are carried out less often across grade levels. For in school computer use, not many differences were found between boys and girls, nor between Dutch natives and immigrants. However, at Southside the computer is used considerably more for drawing and at Central for searching the Internet. It is not clear whether this is due to the 
socio-economic background of the school population or if this has more to do with other factors, such as the educational view of the school team (De Koster, Kuiper \& Volman, 2009).

It is no surprise that outside school, older children (grade 2) use the computer more often and also are more able to operate the computer for a variety of activities than younger ones (pre$\mathrm{K})$. Literature has long suggested that pupil attitudes toward computers are favorable (De Klerk Wolters, 1989; Knezek, 1993; Melissen, 2005); this is consistent with the findings from this study. In addition, this study found that older children have a more positive attitude towards computers than younger children have.

Concern about girls' lack of interest in technology has been growing in the last decade (AAUW, 2000; Meelissen 2008). No big differences between boys and girls out of school computer use were found. Also no gender differences were found in the ability level of using various computer activities. These findings concur with those from a recent study in which young girls and young boys were equally likely to be using a home computer (Brooker \& Siraj-Blatchford, 2002) as well as another in which young girls now report using home computers as often, and with as much confidence as boys (Subrahmanyam, Kraut, Greenfield, \& Gross, 2000). While the findings of this study revealed that boys have a comparably more positive attitude towards computers than girls have, both groups remain generally positive. The finding that boys are more positive about computers is not consistent with results from Knezek et al. (1996), reported for slightly older children in grades 1-3. Children's perceptions of computers are also influenced by the software they use. In a gender-bias content analysis of educational software for preschoolers, Sheldon (2004) found significantly more male characters than female characters in preschool educational software, which, she concludes makes it difficult for teachers to address gender diversity and suggests that girls are not as 
valued as boys are. Subsequent research on gender differences in computing would benefit from a deeper look at the software being used.

Literature suggests that ethnic minority children may be disadvantaged by a lack of home experience with computers (Brooker \& Siraj-Blatchford, 2002; Fish et al., 2008). The findings of this study suggest that immigrant children have more exposure to computers out of school than Dutch children from a low socio-economic background. In addition, immigrant children seem to be better able to operate the computer for a number of different activities, searching information on the Internet in particular. An explanation put forth by Southside teachers is that, often, computer use in immigrant families is focused on communication with family members still living in the country of origin. However, more research is necessary to fully understand this finding. No differences between immigrant children and Dutch children were found in attitude towards computers. The findings of this study also suggest that children from a lower socio-economic background use the computer slightly more often outside school compared to middle class children, and have a more positive attitude towards computers. To explore digital equity more carefully, future research on this theme with young children should portray computer use in relation to ethnic background and socio-economic status. Previous studies have shown that middle class parents were more involved in children's computer use, scaffolding and supervising (Brooker \& Siraj-Blatchford, 2002). Further research is necessary to understand how crucial it is that schools take it upon themselves to ensure equal opportunity for less-advantaged children to access the benefits of the more intellectually powerful uses of computer technology (cf. Becker, 2000). For example, in addition to technology access, the [American] National Institute for Community Innovation's five dimensions of digital equity (2003; see also Resta \& Laferrière, 2008) also include: content that is high quality, culturally responsive and open for learners and educators to edit; 
as well as educator skills in using resources effectively for teaching and learning. Judge, Puckett and Bell (2006, p. 59) emphasize this last dimension in their call for attention to "the human element," which includes teacher: technology skills, abilities to integrate technologies effectively; and beliefs that support high expectations for all students.

This study was particularly meant to explore children's perceptions in the age range of pre-Kgrade 2. Previous research has shown that 7-8 year old children were able to use an enjoyment ranking scale similar to the one used in this study (Knezek, Miyashita \& Sakomoto, 1996; Sim, MacFarlane \& Read, 2006), but experience with the self-reporting data of 4-6 year olds remains limited. This study has shown that it is possible to collect selfreporting data at this age level. This study used icon cards to focus young children on the questions being asked. However, symbols may also interfere with understanding the question properly. More research is necessary to improve communication with children about different types of computer applications.

It is known that the benefits of using technology with young children vary with the kind of experiences offered and how frequently the children have access to computers (Haugland, 2000). In their large-scale longitudinal study with kindergarten, first and third grade children, Judge, Puckett and Bell (2006) found that the presence of in-classroom computer areas, frequent use of the Internet, and proficiency in computer use were correlated positively with academic achievement. In contrast, they also found that frequent use of software for reading was correlated negatively with reading achievement. The study reported here has begun to provide information on how young Dutch children use the computer and their frequency of access both in and out of school along with related abilities and attitudes. As our picture of how children are spending their computer time sharpens, further research should be conducted 
into the quality and appropriateness of those experiences. Several resources are already available, including the Haugland Developmental Scale for Software (Haugland \& Wright, 1997), and the evaluation instrument from Children's Technology Review (1998), but additional work in this area is needed. Understanding children's practices and attitudes can inform educators and parents in the search for both developmentally appropriate uses of technology, and a healthy balance between computer use and other means for children to learn and explore the world around them.

\section{Acknowledgements}

Thanks to Ingrid Greven, Andrea Althanning and Maaike Heitink who participated in the data collection for this study. 


\section{References}

AAUW. (2000). Tech Savvy: Educating Girls in the New Computer Age. Washington DC: American Association of University Women Educational Foundation.

Aubrey, C., \& Dahl, S. (2008). A review of the evidence on the use of ICT in the early years foundation stage. Coventry: BECTA.

Becker, H. (2000). Who's wired and who's not: Children's access to and use of computer technology. Children and Computer Technology, 10(2), 44-75.

Brooker, L., \& Siraj-Blatchford, J. (2002). 'Click on Miaow!': how children of three and four years experience the nursery computer. Contemporary Issues in Early Childhood, 3(2), 251-273.

CBS (2007). Centraal Bureau voor Statistieken. Retrieved August 29, 2009 from http://statline.cbs.nl/statweb/.

Children's Technology Review (1998). Children's Software Evaluation Instrument. Flemington, NJ: Children's Technology Review. Available online at http://www.childrenssoftware.com/rating.html.

Cohen, J. (1969). Statistical power analysis for the behavioral sciences. New York: Academic Press.

Cordes, C., \& Miller, E. (2000). Fool's gold: A critical look at computers in childhood. College Park, MD: Alliance for Childhood.

De Jong, M. T., \& Bus, A. G. (2004). The Efficacy of Electronic Books in Fostering Kindergarten Children's Emergent Story Understanding. Reading Research Quarterly, 39(4), 378-393.

De Klerk Wolters, F. (1989). A PATT Study Among 10 to 12-Year-Old Students in the Netherlands. Journal of Technology Education, 1(1). 
De Koster, S., Kuiper, E., \& Volman, M. (2009). A different approach to the integration of ICT in primary education: The school's educational concept as point of departure. Paper presented at the EARLI conference, August 25-29, Amsterdam.

Fish, A. M., Li, X., McCarrick, K., Butler, S. T., Stanton, B., Brumitt, G. A., et al. (2008). Early Childhood Computer Experience and Cognitive Development among Urban Low-Income Preschoolers. Journal of Educational Computing Research, 38(1), 97113.

Haugland, S. (2000). Computers and young children. Eric Digest. Retrieved 20 July, 2008. Haugland, S.W., and Wright, J.L. (1997).Young children and technology: A world of discovery. Needham Heights, MA: Allyn and Bacon.

Judge, S., Puckett, K., \& Bell, S. (2006). Closing the digital divide: Update from the early childhood longitudinal study. The Journal of Educational Research, 100(1), 52-60.

Judge, S., Puckett, K., \& Cabuk, B. (2004). Digital Equity: New Findings from the Early Childhood Longitudinal Study. Journal of Research on Technology in Education, $36(4), 383-396$.

Knezek, G., Miyashita, K. \& Sakamoto, T. (1993). Cross-cultural Similarities in Attitudes toward Computers and the Implications for Teacher Education. Technology, Pedagogy and Education, 2(2), 193-204.

Knezek, G., Miyashita, K.T., \& Sakomoto, T. (1996). Information technology from the child's perspective. In B.A. Collis, G.A. Knezek, K-W. Lai, K.T. Miyashita, W.J. Pelgrum, T.Plomp \& T.Sakomoto, Children and computers in school (pp69-103). Mahwah, NJ: Lawrence Erlbaum.

Marsh, J. (2004). The Techno-Literacy Practices of Young Children. Journal of Early Childhood Research, 2(1), 51-66. 
Marsh, J., Brooks, G., Hughes, J., Ritchie, L., Roberts, S., \& Wright, K. (2005). Digital beginnings: Young children's use of popular culture, media and new technologies. Sheffield: University of Sheffield.

Melissen, M. (2005). Ict: Meer voor Wim dan voor Jet? de rol van het basisonderwijs in het aantrekkelijk maken van informatie en communicatie technologie voor jongens en meisjes [ICT: More for William than Jeannette? The role of primary schooling in making information and communications technologies attractive for boys and girls]. Doctoral dissertation. Enschede: University of Twente.

Meelissen, M. (2008). Computer attitudes and competencies among primary and secondary school students. In J. Voogt \& G. Knezek, International handbook of information technology in primary and secondary education (pp381-395). New York: Springer.

National Institute for Community Innovations (2003). The five dimensions of digital equity. Retrieved 20 July, 2008.

Nikolopoulou, K. (2007). Early Childhood Educational Software: Specific Features and Issues of Localization. Early Childhood Education Journal, 35(2), 173-179.

Pelletier, J., Reeve, R., \& Halewood, C. (2006). Young Children's Knowledge Building and Literacy Development through Knowledge Forum[R]. Early Education and Development, 17(3), 323-346.

Plowman, L., \& Stephen, C. (2003). A 'benign addition'? Research on ICT and pre-school children. Journal of Computer Assisted Learning, 19, 149-164.

Plowman, L., \& Stephen, C. (2007). Guided interaction in pre-school settings. Journal of Computer Assisted Learning, 23, 14-26.

Resta, P. \& Laferrière, T. (2008). Issues and challenges related to digital equity. In J. Voogt \& G. Knezek, International handbook of information technology in primary and secondary education (pp765-778). New York: Springer. 
Sheldon, J. (2004). Gender stereotypes in educational software for young children. Sex Roles, $51(7 / 8), 433-444$.

Sim, G., MacFarlane, S., \& Read, J. (2006). All Work and No Play: Measuring Fun, Usability, and Learning in Software for Children. Computers and Education, 46(3), 235-248.

Siraj-Blatchford, J., \& Siraj-Blatchford, I. (2001). Kidsmart: The Phase 1 UK Evaluation 2000-2001. Retrieved August 24, 2009, from http://www.327matters.org/Docs/IBM.pdf

Siraj-Blatchford, J., \& Siraj-Blatchford, I. (2002). Developmentally appropriate technology in early childhood: Video conferencing. Contemporary Issues in Early Childhood, 3(2), 216-225.

Siu, K. W. M., \& Lam, M. S. (2005). Early Childhood Technology Education: A Sociocultural Perspective. Early Childhood Education Journal, 32(6), 353-358.

Skeele, R., \& Stefankiewicz, G. (2002). Blackbox in the Sandbox: The Decision To Use Technology with Young Children with Annotated Bibliography of Internet Resources for Teachers of Young Children. Educational Technology Review, 10(2).

Subrahmanyam, K., Kraut, R., Greenfield, P., \& Gross, E. (2000). The impact of home computer use on childrens activities and development. Children and Computer Technology, 10(2), 123-144.

Ten Brummelhuis, A. C. A. \& Drent, M. (2000). ICT monitor 1998 - 1999 Basisonderwijs [ICT monitor 1998-1999 Elementary Education]. Enschede: University of Twente.

Wartella, E., \& Jennings, N. (2000). Children and Computers: New Technology-Old Concerns. Children and Computer Technology, 10(2), 31-43.

Yelland, N., Neal, G. \& Dakich, E. (2008). Rethinking education with ICT: New directions for effective practices. Rotterdam, Netherlands: Senses Publishing. 


\section{Figure Captions}

Figure 1: Two icon cards used during the interview (left=drawing, right=games)

\section{Tables}

Table 1: Overview of the 2003 and 2007 data collection

Table 2: Availability of a computer at home (with Internet) with respect to gender, socioeconomic status and ethnic groups (in \%)

Table 3: The location where children report using computers most outside of school hours (in $\%)$

Table 4: Percentage of children that report 'never' using a specific computer activity in school or outside school

Table 5: Children's self report of computer use in school and out of school according to gender

Table 6: Children's self report of computer use in school according to grade level

Table 7: Children's self report of computer use outside school according to grade level

Table 8: Southside children's self report of computer use in school and out of school for

Dutch natives and immigrants

Table 9: Children's self report of computer use in school and out of school to socio-economic status

Table 10: Children's self report of skills necessary for computer activities (with help or alone in \%) according to gender and grade level

Table 11: Children's self report of skills necessary for computer activities (with help or alone in \%) according to ethnic group and socio-economic status

Table 12: Differences between gender, grade level, socio-economic status and ethnic group in attitudes towards computers 